\title{
Growth hormone insensitivity: Mexican case report
}

\section{Castilla-Cortazar1,2, J R De Ita1, G A Aguirre', M García-Magariño1, I Martín-Estal', V J Lara-Diaz' and M I Elizondo'}

'Escuela de Medicina, Tecnologico de Monterrey, Monterrey, México and 2Fundación de Investigación HM Hospitales, Madrid, Spain
Correspondence should be addressed to I Castilla de Cortázar Larrea

Email

iccortazar@itesm.mx

\section{Summary}

Herein, we present a 14-year-old patient with short stature $(134 \mathrm{~cm})$ referred from Paediatrics to our department for complementary evaluation since growth hormone $(\mathrm{GH})$ treatment failed to show any improvement. He was born premature and small for gestational age. Genital examination classified the patient as Tanner I-II with small penis and testicular size for his age. Biochemical analyses revealed normal GH levels with low serum insulin-like growth factor-1 (IGF-1). Molecular diagnosis confirmed several mutations in IGF1R and IGFALS, and so he was diagnosed with Laron Syndrome or GH insensibility and treated with IGF-1 substitutive therapy.

\section{Learning points:}

- Evaluation of the GH/IGF-1 axis when short stature does not respond to conservative treatment must be included in the ordinary practice.

- Laron Syndrome real incidence should be calculated once undiagnosed cases arise, as treatment, due to lack of market, is unaffordable.

- Even when adulthood is reached, and no longitudinal growth can be achieved, still IGF-1 treatment in Laron Syndrome patients should be pursued as metabolic and protective derangements could arise.

\section{Background}

Laron Syndrome was first discovered in 1958 when Zvi Laron was presented with two children with growth retardation (1). However, at the time, no immunoassay for growth hormone $(\mathrm{GH})$ was available. In the subsequent years, Laron gathered 22 children with the same features, who all belonged from the Middle East or Arabian Peninsula (1). Their characteristics were dwarfism (reaching sizes of -4 to -8 SDS (1)), obesity with dyslipidaemia (due to metabolic derangements reaching in some cases fatty liver (1)), small genitalia in the boys and increased lower/ upper body ratio (denoting short limbs) in females and severe hypoglycaemia in children with later glucose intolerance even developing Type 2 Diabetes and cardiovascular disease (1). Head configuration presented small face with a protruding forehead, and saddle nose together with a below normal head circumference (1). They also had high pitched voice and sparse hair. Back then, they were diagnosed as dwarfism with insulininduced hypoglycaemia (1).

The typical phenotype usually varies as a consequence of the type of mutation associated and the degree of GH resistance; thus, the clinical characteristics of this patient are not always the classic clinical manifestation of Laron Syndrome, further hindering the diagnosis.

Later on, when GH immunoassays were available, it was found that these children had markedly elevated serum GH levels (1). With technological advances, it could be seen that GH itself was genetically and structurally 
normal (1). Moreover, exogenous GH administration did not show any response or provoked a rise in serum insulin-like growth factor-1 (IGF-1) (1), which is secreted by the liver following GH stimulus. It was not until 1984 that 'GH resistance' per se was proven, when Laron, using I $125 \mathrm{rGH}$, found that it did not attach to liver membranes in contrast to healthy controls (1) and further confirmed when cloning the GH receptor (GHR) in two of the patients revealing a partial gene deletion (2). Since the arrival of the PCR technique, numerous mutations in the GHR gene were identified (1). Treatment with rhIGF-1 of Laron Syndrome children in doses ranging from 150 to $220 \mu \mathrm{g} / \mathrm{kg}$ once daily (which showed some benefit when taken with the meal rather than twice daily (1)) resulted in rapid height, brain, head circumference and organ growth $(1,3,4)$. There is, however, still a little controversy regarding metabolic outcomes of the treatment, where it has shown to benefit metabolism by slightly reducing adiposity and lipidaemia, improving glucose and lipid profiling and insulin sensitivity $(1,5)$, but still retaining adiposity and lipidaemia reaching marked obesity and the end of puberty (1). Epidemiological data are hard to establish since the majority of cases remain undiagnosed due to treatment costs or failure to identify, i.e. diagnosed with idiopathic short stature. Nonetheless, to date, the major cohorts of Laron Syndrome patients have been identified in Israel with approximately 70 patients, Ecuador with over 100 patients, Chile, Brazil, and one US patient of Mexican origin, estimating a total of roughly 250 patients world-wide $(1,6)$.

\section{Case presentation}

A 14-year-old Mexican male with short stature (Fig. 1) presented to our department for genetic and complementary evaluation due to rhGH-unresponsive short stature. His family history included aplastic anaemia, melanoma, hypertension and diabetes mellitus.

He was prematurely born at 26 weeks weighing $1500 \mathrm{~g}$, from non-consanguineous healthy parents of same ethnic origin (Yucatán, México), the father having Jewish descent. At birth, he was diagnosed with respiratory failure and was treated with nasal continuous positive airway pressure and exogenous surfactant, with complete functional recovery. He had sub-coronal hypospadias and chordae, which were surgically resolved. Overall, he spent one and a half months being hospitalised, and was further discharged with no complications.

Throughout his childhood, he presented short stature, referring to always being the shortest in his classroom,

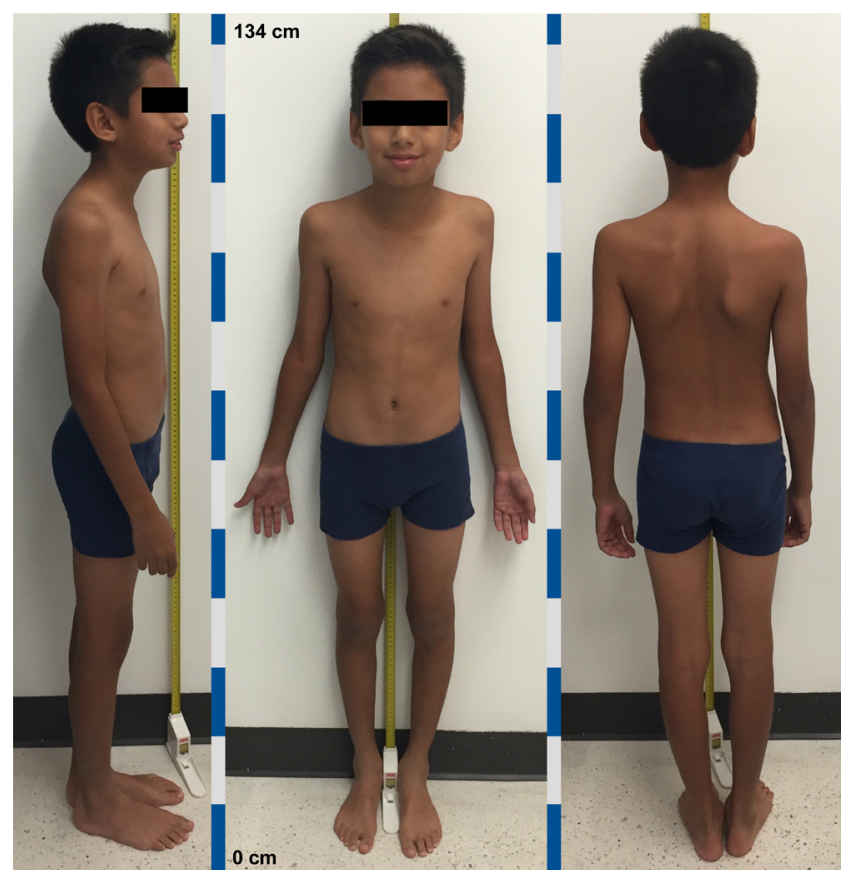

Figure 1

Physical examination. Abnormally low short stature, $134 \mathrm{~cm}$ (-14 SDS below 3rd percentile for age).

with growth curves uniformly below the third percentile (Fig. 2). At the age of 12 years, he was evaluated by a paediatric endocrinologist, and on his advice started a treatment with $\mathrm{GH}$, without any response.

Clinically, he has a normal cognitive development, a short stature without skeletal complications. He has no cardiac-, respiratory-, digestive- or urinary-related symptoms.

\section{Investigation}

Physical examination revealed a 14-year-old male with an apparent age under the chronological one, a stature of $134 \mathrm{~cm}$ ( -14 SDS below 3rd percentile for age), and a weight of $25.3 \mathrm{~kg}$ ( $-13 \mathrm{SDS}$ below 3rd percentile for age): see Fig. 1 which displays symmetric and well-developed limbs. He had no dental, skin or nail abnormalities. Genital examination classified the patient as Tanner I (underdeveloped for a 14-year-old, no puberty), with testicular dimensions of $7 \mathrm{~cm}^{3}$ and a penis size $4 \mathrm{~cm}$.

Laboratory tests displayed IGF-1 $161 \mathrm{ng} / \mathrm{mL}(-2.2$ $Z$ score), IGFBP-3: $4.0 \mathrm{mg} / \mathrm{L}$ (reference range for his age: $3.3-10 \mathrm{mg} / \mathrm{L}$ ) and a normal GH curve (basal value: $0.32 \mathrm{ng} / \mathrm{mL}$ with a maximal clonidine stimulation peak at $90 \mathrm{~min}$ of $11.70 \mathrm{ng} / \mathrm{mL}$ ). Results for blood cell count and urine analysis were normal; however, biochemical profile showed moderate elevation of urea and nitrogen, elevated 
A

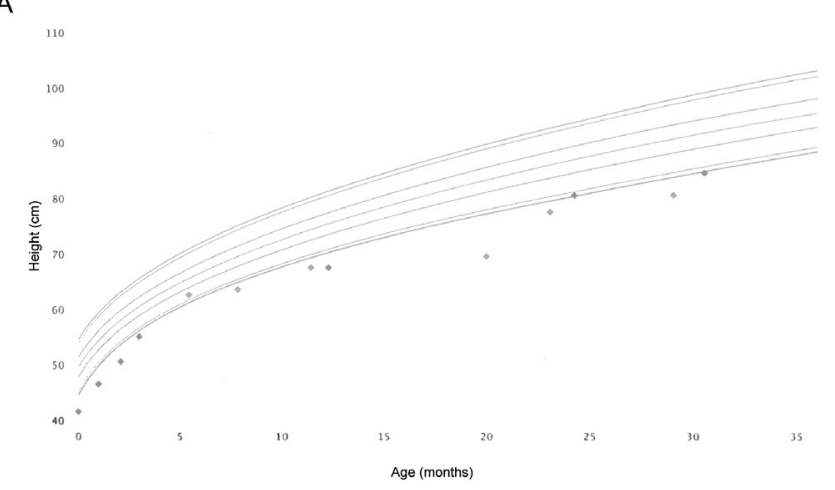

B

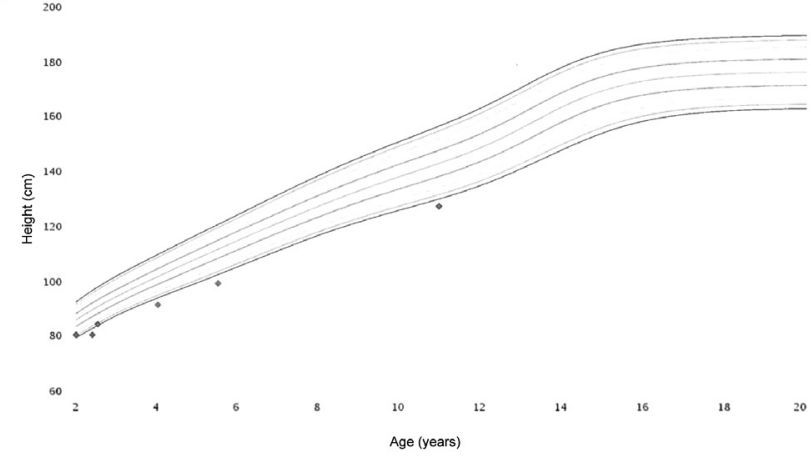

Figure 2

Age-height growth curve. (A) For the first 35 months of age, and (B) from 3 to 12 years of age. Points in the graph represent the patient's height at the indicated age in the context of the normal growth, represented by percentile (percentile 3 to percentile 97) lines.

cholesterol: $197 \mathrm{mg} / \mathrm{dL}$ (upper reference limit: $170 \mathrm{mg} / \mathrm{dL}$ ) and diminished phosphorus: $4.3 \mathrm{mg} / \mathrm{dL}$ (lower reference limit: $4.5 \mathrm{mg} / \mathrm{dL}$ ). Total thyroxine (T4), free thyroxine (FT4), thyroxine uptake (T4U), total triiodotrhyronine (T3) and thyroid-stimulating hormone were all within normal reference limits for his age.

\section{Molecular diagnosis}

Variants were analysed by NextGen whole exome sequencing (WES). The samples were prepared according to an Agilent SureSelect v5 (Agilent Technologies) Target Enrichment Kit preparation guide. The libraries were sequenced with Illumina HiSeq 2000/2500 sequencer (Illumina, San Diego, CA, USA). WES revealed a series of variants impacting the GH/IGF-1 axis, as depicted in Table 1, and discarded any disturbances in the hypophysis-pituitary GH generation pathway. A compound intronic mutation was found on the IGF1R gene, one of the variants being homozygous. All the three variants gave positive results from algorithms calculating

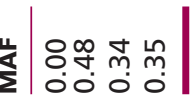

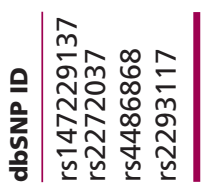

|
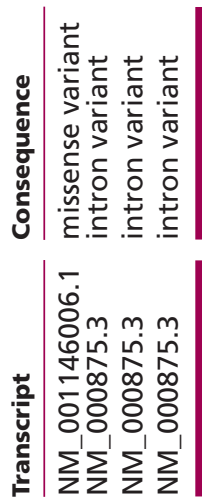

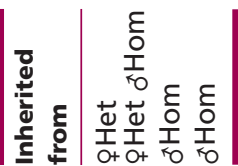

穵|

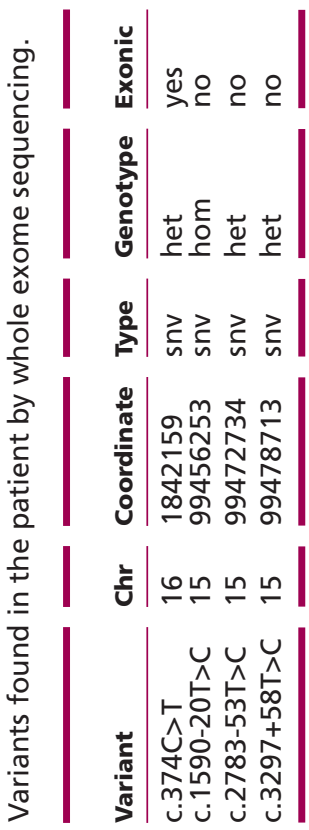

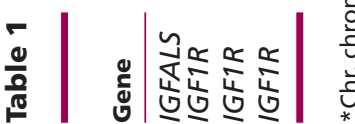


splicing impact (SSF, MaxEnt, NNSPLICE, GeneSplicer) that predicted severe changes in acceptor sites. Only rs2293117 has been reported before (7) as part of a cohort of low-birth weight-related causes. Also, a heterozygous exonic variant was found on the IGFALS gene, catalogued by Sift algorithm as deleterious (0.05) which has never been reported before, changing a polar amino acid (Ser) for a hydrophobic one (Leu).

\section{Treatment and follow-up}

The patient started IGF-1 substitutive therapy (Increlex, Ipsen, USA) as soon as his parents found the funding for it. IGF-1 substitutive therapy will be the treatment applied as the patient is still in age to grow and fully develop as well as to aim metabolic derangements derived from the altered GH/IGF-1 axis $(1,5)$.

After multiple vicissitudes to introduce the treatment in México, we started the replacement therapy with IGF-1 (Increlex) at the age of 14 years 10 months (with a bone age of 11 years) and also started with a dose of $0.04 \mathrm{mg} /$ $\mathrm{kg}$ of body weight twice daily by subcutaneous injection; no significant adverse reactions occur for 2 weeks and the dose raised in increments from $0.04 \mathrm{mg} / \mathrm{kg}$ to the maximum dose of $0.12 \mathrm{mg} / \mathrm{kg}$ given twice daily, with monthly follow-up starting from October 2016 (Table 2).

Throughout the follow-up, the patient has presented as side effect pain at the application site. He recently suffered from suppurative acute appendicitis. Since the first application of Increlex, the patient has grown a total of $9 \mathrm{~cm}, 1$ stage of Tanner and $3 \mathrm{~cm}$ of foot. In addition to the improvement in height, there has been a dramatic change in his self-esteem and self-perception, his interpersonal relationships and greater self-confidence.

\section{Discussion}

Herein, we present a patient diagnosed with GH insensitivity (GHI). Clinical features (premature, severe short stature, genital underdevelopment and no response to GH therapy) and endocrine analysis (low IGF-1 and normal GH) suggested a Laron Syndrome patient. GH-stimulation test peak does not fully match with classical GHI; however, it is now known that there are numerous factors that could affect the test and that such tests lack reproducibility (8).

The variants discovered in the patient clearly confirm the GHI diagnosis and phenotype. Mutations in IGFALS have shown to cause GHI phenotype, although in homozygosity and with a less severe phenotype $(9,10)$. This patient possesses the mutation in heterozygosity; however, this mutation seems to have bad outcomes, the amino acid change chemistry is high and is not represented among the population (MAF=0.00004). Together with this, the compound variants located in IGF1R could add severity to the case, however impacting slightly in splicing sites at different exons, and two of them found in heterozygosity. Because the three IGF1R mutations are represented in the population (MAF=0.34-0.48), they may not impact full expression of the protein. Adding to this, the fact that the patient is responding to IGF-1 therapy indicates that a sufficient amount of IGF1R is functional. However, both affected genes in the same context give rise to the phenotype herein depicted. It seems relevant to mention the short stature acquired from the mother's family and the Jewish descent of the father (reported origin of Laron Syndrome). This correlates with the genetic alterations observed, where the father contributed with the mutations in IGF-1R in homozygosity (and one heterozygous from the mother), and the mother contributed with the IGFALS in heterozygosity, that when they combined in the offspring gave rise to the phenotype described.

Efficacy of IGF-1 substitutive therapy was very noticeable; besides growth and development, a strong psychological improvement was perceived, despite the late initiation of treatment (almost 15 years of age). The delay was occasioned by both complications in molecular diagnosis and treatment access in México (legal, governmental and economic reasons). There is an urgent need for governments to reconsider access to IGF-1 in México and Latin American countries, where there is a big necessity for it, not just for growth disorders,

Table 2 Patient Follow-up since the onset of IGF-1 substitutive treatment.

\begin{tabular}{|c|c|c|c|c|c|c|c|}
\hline Month & Year & Height $(\mathrm{cm})$ & $\begin{array}{l}\text { Tanner } \\
\text { stage }\end{array}$ & $\begin{array}{c}\text { Shoe size } \\
\text { increment }(\mathrm{cm})\end{array}$ & IGF-1 (ng/mL) & $\begin{array}{l}\text { Carcinoembryonic antigen } \\
(\mathrm{ng} / \mathrm{mL})\end{array}$ & $\begin{array}{l}\text { Glucose } \\
\text { (mg/dL) }\end{array}$ \\
\hline October & 2016 & 138 & 2 & - & 239 & 1.42 & 75 \\
\hline November & 2016 & 141.9 & 2 & - & - & - & - \\
\hline February & 2017 & 143 & 3 & 2 & 746 & 1.32 & 71 \\
\hline May & 2017 & 147 & 3 & 1 & - & - & - \\
\hline
\end{tabular}


but also for metabolic disorders derived from chronic IGF-1 deprivation.

The patient did not show any unwanted effect other than pain at site of injection and even there was a downwards tendency of the Embryo-carcinogenic Antigen (from 1.42 to $1.32 \mathrm{ng} / \mathrm{mL}$ ).

Clinical manifestations, biochemical results and genetic characterisation confirm a Mexican GHI patient. We propose recombinant human IGF-1 substitutive treatment as the course of action.

\section{Declaration of interest}

The authors declare that there is no financial or other potential conflict of interest that could be perceived as prejudicing the impartiality of the research reported.

\section{Funding}

All procedures were funded by Tecnológico de Monterrey.

\section{Patient consent}

All procedures and images were carried out under a written patient's informed consent without any coercion and approval from Clinical Ethics Committee from Tecnologico de Monterrey was also obtained.

\section{Author contribution statement}

C C I: clinical diagnosis, carried out and established the techniques to confirmed diagnosis, paper writing; IJR: clinical procedures and paper writing; A G A: contributed to the processing of samples, established molecular diagnosis, literature review and paper writing; $\mathrm{G} \mathrm{M} \mathrm{M:}$ contributed in sample extraction and processing; $\mathrm{M} E$ I: figure design and sample processing; L D V J: introduced the patient to our facility and finally, E M I: contributed to molecular diagnosis and literature review.

\section{Acknowledgements}

The authors would like to express their gratitude to Zvi Laron's admirable labour; alike him, Mexican physicians aim to improve current standard of treatment for primary growth hormone insensitivity and plausible severe consequences that never-treated patients would develop.

\section{References}

1 Laron Z \& Kauli R 2016 Fifty seven years of follow-up of the Israeli cohort of Laron Syndrome patients-From discovery to treatment. Growth Hormone and IGF Research : Official Journal of the Growth Hormone Research Society and the International IGF Research Society $\mathbf{2 8}$ 53-56. (doi:10.1016/j.ghir.2015.08.004)

2 Godowski PJ, Leung DW, Meacham LR, Galgani JP, Hellmiss R, Keret R, Rotwein PS, Parks JS, Laron Z, \& Wood WI 1989 Characterization of the human growth hormone receptor gene and demonstration of a partial gene deletion in two patients with Laron-type dwarfism. PNAS 86 8083-8087. (doi:10.1073/ pnas.86.20.8083)

3 Fintini D, Brufani C, \& Cappa M 2009 Profile of mecasermin for the long-term treatment of growth failure in children and adolescents with severe primary IGF-1 deficiency. Therapeutics and Clinical Risk Management 5 553-559. (doi:10.2147/TCRM.S6178)

4 Kemp SF 2009 Insulin-like growth factor-I deficiency in children with growth hormone insensitivity: current and future treatment options. BioDrugs : Clinical Immunotherapeutics, Biopharmaceuticals and Gene Therapy 23 155-163. (doi:10.2165/00063030-200923030 00002)

5 Aguirre GA, De Ita JR, de la Garza RG \& Castilla-Cortazar I 2016 Insulin-like growth factor-1 deficiency and metabolic syndrome. Journal of Translational Medicine 14 3. (doi:10.1186/s12967-0150762-z)

6 Rosenbloom AL 2016 A half-century of studies of growth hormone insensitivity/Laron syndrome: a historical perspective. Growth Hormone and IGF Research : Official Journal of the Growth Hormone Research Society and the International IGF Research Society 28 46-50. (doi:10.1016/j.ghir.2015.08.001)

7 Edwards DRV, Romero R, Kusanovic JP, Hassan SS, Mazaki-Tovi S, Vaisbuch E, Kim CJ, Erez O, Chaiworapongsa T, Pearce BD, et al. 2011 Polymorphisms in maternal and fetal genes encoding for proteins involved in extracellular matrix metabolism alter the risk for smallfor-gestational-age. Journal of Maternal-fetal and Neonatal Medicine 24 362-380. (doi:10.3109/14767058.2010.497572)

8 Chinoy A \& Murray PG 2016 Diagnosis of growth hormone deficiency in the paediatric and transitional age. Best Practice and Research Clinical Endocrinology and Metabolism 30 737-747. (doi:10.1016/j.beem.2016.11.002)

9 David A, Hwa V, Metherell LA, Netchine I, Camacho-Hübner C, Clark AJL, Rosenfeld RG, \& Savage MO 2011 Evidence for a continuum of genetic, phenotypic, and biochemical abnormalities in children with growth hormone insensitivity. Endocrine Reviews 32 472-497. (doi:10.1210/er.2010-0023)

10 Wit JM \& de Luca F 2016 Atypical defects resulting in growth hormone insensitivity. Growth Hormone and IGF Research 28 57-61. (doi:10.1016/j.ghir.2015.11.005)

Received in final form 20 September 2017

Accepted 19 October 2017 